\title{
Pencegahan dan Pengendalian Infeksi di RSJ Dr. Radjiman Wediodiningrat Lawang: Apa Kendala Pelaporannya?
}

\section{Prevention and Control of Infection at Dr. Radjiman Wediodiningrat Mental Hospital Lawang: What are the reporting constraints?}

\author{
Imelda Fitria $D^{1}$, Nurul Sri HR², Lukman Hakim ${ }^{1}$ \\ ${ }^{1}$ Program Studi Magister Manajemen Rumah Sakit Fakultas Kedokteran Universitas Brawijaya Malang \\ ${ }^{2}$ Rumah Sakit Jiwa Dr Radjiman Wediodiningrat Lawang
}

\begin{abstract}
ABSTRAK
Program pencegahan dan pengendalian infeksi (PPI) merupakan salah satu tolok ukur mutu pelayanan rumah sakit yang diukur secara berkala oleh komite PPI. Studi pendahuluan menunjukkan capaian indikator mutu komite PPI di RSJ Dr. Radjiman Wediodiningrat tahun 2014 masih di bawah standar. Capaian tahun 2015 sudah sesuai target tetapi masih ditemukan banyak kendala dalam pencatatan dan pelaporan form. Kendala tersebut yaitu belum semua ruangan menyerahkan laporan rutin setiap bulannya paling lambat tanggal 10. Tujuan penelitian ini adalah untuk melihat pengaruh sosialisasi pencatatan dan pelaporan form PPI terhadap dampak pengembalian form PPI ke IPCN, untuk mengidentifikasi, menganalisis, dan menentukan faktor yang mempengaruhi ketidaktepatan pengembalian pelaporan form PPI di RSJ Dr. Radjiman Wediodiningrat. Penelitian dilakukan dengan pendekatan deskriptif kualitatif dengan membandingkan hasil pre dan post sosialisasi, wawancara tidak terstruktur. Hasil penelitian menunjukkan peningkatan angka pengembalian form pelaporan PPI yang kurang bermakna (dari 64,29\% menjadi 67,86\%). Dari hasil wawancara pada 25 ruangan rawat inap didapatkan penyebab terbesar karena komponen pelaporan form PPI terlalu banyak. Penyederhaan form yang diikuti dengan pelatihan dan monitoring evaluasi berkelanjutan disarankan sebagai solusi definitif untuk meningkatkan kinerja pelaporan infeksi di rumah sakit.
\end{abstract}

Kata Kunci: Infection Prevention and Control Nurse (IPCN), pencegahan dan pengendalian infeksi, PPI, sosialisasi pencatatan dan pelaporan form PPI

\begin{abstract}
Infection prevention and control program is one of the hospital quality indicators which was measured periodically by the infection prevention and control committee. Preliminary study showed that the committee's quality indicator achievement was still below standard. Although in 2015 quality enhancement was already shown, there were many obstacles in recording and reporting form that not all of the inpatient ward reported the form on time before $10^{\text {th }}$ each month. This study aims to see the impact of recording and reporting socialization on the form's returning to the IPCN, to identify, to analyze, and to determine factors that affects inaccuracies of form at Dr. Radjiman Wediodiningrat Mental Hospital. This study was conducted with a qualitative descriptive approach by comparing the pre and post socialization results and nonstructured interview. The result shows higher number of returned form (from 64,29\% to 67,86\%). From the interview results from 25 wards, there were too many reporting points or items on the form. To simplify the form followed with training and continuous evaluation are recommended as a definite solution to improve infection reporting achievement at the hospital.
\end{abstract}

Keywords: Infection prevention and control, Infection Prevention and Control Nurse (IPCN), socialization on recording and reporting infection prevention and control form

Korespondensi: Imelda Fitria D. Program Studi Magister Manajemen Rumah Sakit Fakultas Kedokteran Universitas Brawijaya Malang, Jl. Veteran Malang Jawa Timur Tel. (0341) 568989 Email: imelda.donosepoetro@gmail.com 


\section{PENDAHULUAN}

World Health Organization mengungkapkan, infeksi nosokomial atau yang disebut health care-associated infections (HAls), adalah adverse effect (efek yang tidak diinginkan) yang paling sering terjadi di pelayanan kesehatan di seluruh dunia. Ratusan juta pasien mengalami kejadian infeksi nosokomial kesehatan setiap tahunnya, yang mengarah kepada morbiditas, mortalitas, dan kerugian finansial di bidang kesehatan (1). Infeksi nosokomial mengakibatkan penggunaan sumber daya rumah sakit yang lebih besar dari biasanya. Dengan pencegahan yang baik, maka penggunaan sumber daya tersebut dapat diminimalkan(2-5).

Program pencegahan dan pengendalian infeksi (PPI) di rumah sakit merupakan salah satu standar mutu pelayanan rumah sakit. Pengendalian infeksi harus dilaksanakan oleh semua rumah sakit dan fasilitas pelayanan kesehatan lainnya untuk melindungi pasien, petugas kesehatan dan pengunjung dari kejadian infeksi yang tidak diharapkan dengan memperhatikan cost effectiveness yang meliputi perencanaan, pelaksanaan, pembinaan, pendidikan dan pelatihan, serta monitoring dan evaluasi. Pelaksanaan PPI di rumah sakit harus dikelola dan diintegrasikan antara struktural dan fungsional di semua instalasi di rumah sakit sesuai dengan falsafah dan tujuan PPI, sehingga dapat menunjang visi dan misi rumah sakit. Infeksi nosokomial saat ini telah menjadi salah satu tolok ukur mutu pelayanan rumah sakit, dimana angka kejadian infeksi nosokomial tidak boleh lebih dari $9 \%$.

Pada tahun 2015 capaian indikator mutu PPI sudah tercapai dengan baik. Dari hasil Focus Group Discussion (FGD) dengan tim PPI, walaupun capaian semester I tahun 2015 sudah baik, tetapi terdapat kendala dalam hal pelaporan form kegiatan PPI. Kegiatan PPI juga meliputi pencatatan dan pemantauan yang dilakukan di setiap instalasi yang ada di RSJ Dr. Radjiman Wediodiningrat. Pelaporan dan pencatatan yang diutamakan adalah dari instalasi rawat inap yang meliputi form kepatuhan hand hygine, form ketersediaan alat pelindung diri (APD), form ketersediaan fasilitas PPI, form surveilans PPI, dan form monitoring kepatuhan penggunaan APD. Kendala dalam pelaporan form PPI adalah tidak semua instalasi rawat inap menyerahkan pelaporan form PPI tepat waktu sesuai dengan yang telah ditentukan yaitu tanggal 10 setiap bulannya.

Hasil analisis menggunakan diagram tulang ikan dengan metode focus group discussion dengan tim PPI dan didapatkan faktor-faktor penyebab rendahnya pelaporan dari aspek people, plant, dan procedures. Hal-hal yang mempengaruhi ketidaktepatan waktu pelaporan form PPI dari faktor people antara lain karena sosialisasi standar prosedur operasional belum efektif, individu yang suka menunda, IPCLN yang takut mencatat kepatuhan dari staf lain, IPCLN tidak tahu kepentingan mencatat, dan dianggap menambah beban kerja. Hal yang dirasa mempengaruhi dari faktor plant adalah karena kurang dilakukan pelatihan internal untuk IPCLN. Hal yang dirasa mempengaruhi dari faktor procedures adalah karena monitoring pimpinan dan atau IPCN belum merata dilakukan di seluruh instalasi.

Berdasarkan akar masalah tersebut, penulis mengusulkan tiga alternatif solusi yang berupa rencana aksi, yaitu mengadakan program pelatihan intern untuk IPCLN, monitoring IPCN ke seluruh instalasi secara rutin, dan sosialisasi prosedur pencatatan dan pelaporan form PPI. Dari hasil diskusi pada kegiatan supervisi pertama tersebut, diputuskan solusi yang akan dilakukan dalam program magang ini adalah berupa sosialisasi prosedur pencatatan dan pelaporan form PPI. Sosialisasi ditujukan kepada kepala ruangan instalasi rawat inap di RSJ Dr. Radjiman Wediodiningrat Lawang dengan pertimbangan karena kepala ruang sebagai pimpinan staf di instalasi yang dapat memberikan pengaruh positif terhadap kinerja staf diruangan.

Max Weber et al, menyebutkan, sosialisasi merupakan suatu proses yang berperan penting dalam pembelajaran seseorang untuk dapat mempelajari pola hidup sesuai dengan nilai, norma, serta kebiasaan yang dijalankan di dalam suatu masyarakat atau kelompok (6). Tujuan sosialisasi adalah untuk memberikan keterampilan, mengembangkan kemampuan, untuk menanamkan nilainilai, serta kepercayaan seseorang dalam bermasyarakat $(6-8,9)$. Perlunya sosialisasi tentang pencatatan dan pelaporan form PPI ini diharapkan agar kepala ruangan dapat memahami sepenuhnya tentang pentingnya pencatatan dan pelaporan form PPI sehingga dapat memberikan instruksi yang tegas kepada IPCLN di ruangan. Sosialisasi perlu dilakukan terus menerus baik setiap terdapat pembaruan SPO, terbitnya SPO baru, atau sebagai upaya pemeliharaan dan perbaikan kegiatan PPI, agar dapat dipahami dan dilaksanakan oleh seluruh petugas kesehatan di rumah sakit (10).

Tujuan dari penelitian ini adalah untuk melihat dampak sosialisasi terhadap waktu pengembalian form PPI berkaitan dengan pemahaman pimpinan/kepala ruangan, IPCLN, dan perilaku mereka serta mengidentifikasi faktorfaktor yang mempengaruhi ketidaktepatan waktu pengembalian form PPI dari ruangan instalasi rawat inap kepada IPCN. Penelitian ini diharapkan dapat memberikan rekomendasi dan upaya perbaikan atas permasalahan pencatatan dan pelaporan form PPI di RSJ Dr. Radjiman Wediodiningrat Lawang.

\section{METODE}

Rancangan penelitian yang digunakan adalah dengan penelitian deskriptif dengan membandingkan hasil pre dan post sosialisasi yang menggabungkan data kuantitatif dan kualitatif. Hasil yang dibandingkan adalah capaian pengembalian form PPI yang diserahkan kepada IPCN sebelum diadakan sosialisasi, dan setelah diadakan sosialisasi untuk melihat apakah ada pengaruh sosialisasi terhadap ketepatan waktu pengembalian form PPI dengan batas pengembalian form PPI adalah tanggal 10 setiap bulannya. Penelitian dilakukan di RSJ Dr. Radjiman Wediodiningrat Lawang pada Bulan September-Oktober 2015. Penelitian ini melibatkan kepala ruang dan IPCLN sebagai responden.

Sosialisasi dilaksanakan pada akhir Bulan September 2015 dan dihadiri oleh 27 kepala ruangan dari total 28 ruangan yang ditargetkan. Sosialisasi dilakukan dengan cara penyampaian secara langsung oleh pembicara kepada peserta sosialisasi dengan menggunakan form kosong PPI untuk memberi petunjuk pengisian kepada peserta. Materi sosialisasi berisi tentang bagaimana alur perjalanan form PPI mulai dari IPCN, ke ruangan instalasi rawat inap, dan dikembalikan lagi kepada IPCN, materi kedua berisi tentang bagaimana cara atau prosedur pencatatan yang dilakukan di ruangan instalasi rawat inap, siapa yang 
melakukan pencatatan dan observasi staf di ruangan, bagaimana pelimpahan wewenang apabila petugas IPCLN sedang tidak bertugas, dan kapan form laporan PPI tersebut harus terisi dan dilaporkan atau dikembalikan kepada IPCN setiap bulannya. Media sosialisasi menggunakan form PPI kosong sebagai media peraga, dan papan tulis. Teknik sosialisasi yang dilakukan penulis mengadopsi dari Teori Komunikasi Harold Laswell dimana komunikasi yang baik meliputi lima unsur yaitu siapakah pembicaranya, apa yang disampaikan (what), apa media nya (channel/medium), siapakah pendengarnya (whom), dan bagaimana efeknya (effect) (11).

Setelah melakukan sosialisasi, perkembangan pengembalian form PPI kepada IPCN diperhatikan, paling lambat tanggal 10 Oktober 2015, atau sebagai nilai post sosialisasi. Hasil pre sosialisasi dihasilkan dari angka ketepatan waktu pengembalian form PPI yang telah dikumpulkan atau paling lambat tanggal 10 September 2015 dengan melihat buku laporan penyerahan form di kantor PPI. Metode selanjutnya adalah telusur ke ruangan instalasi rawat inap untuk mengetahui penyebab ketidaktepatan waktu pengumpulan laporan. Teknik wawancara tidak terstruktur kepada seluruh kepala dan IPCLN ruangan rawat inap digunakan untuk menggali penyebab terbesar ketidakpatuhan pengembalian form PPI. Poin pertanyaan dalam wawancara tidak terstruktur tersebut adalah menanyakan 2 hal, yang pertama adakah kendala mengenai pencatatan form PPI, dan apakah saran bagi form PPI sebaiknya. Dari 28 ruangan, yang berhasil diwawancarai adalah sebanyak 25 ruangan. Tiga ruangan tidak dapat diwawancarai karena pada saat penyusun mengunjungi ruangan tersebut, kepala ruangan dan IPCLN tidak di tempat, dan perawat pelaksana di ruangan tidak mengetahui mengenai pelaporan PPI.

\section{HASIL}

\section{Dampak sosialisasi}

Dampak sosialisasi dilihat dengan membandingkan hasil pre sosialisasi yaitu data pelaporan form bulan Agustus 2015, dengan hasil post sosialisasi yaitu data pelaporan form bulan September 2015. Target pengumpulan form PPI tepat waktu adalah sebanyak 28 ruang instalasi rawat inap di RSJ Dr. Radjiman Wediodiningrat. Hasil sosialisasi pada Bulan Agustus menunjukkan peningkatan yang kurang bermakna dengan peningkatan angka pengembalian form tepat waktu ke IPCN hanya 3,57\% pada bulan September (Gambar 1).

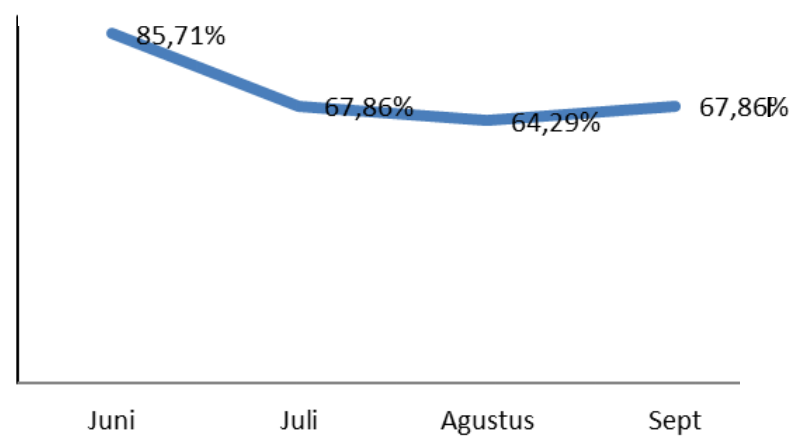

Grafik 1. Proporsi form yang dikumpulkan tepat waktu periode bulan Juni - Agustus 2015

\section{Penyebab Ketidaktepatan Waktu Pengembalian Form}

Hasil telusur menunjukkan tiga faktor terbanyak kendala pelaporan form PPI yaitu poin pelaporan form terlalu banyak (sebesar 36\%), kurangnya fasilitas (sebesar 16\%), dan faktor pasien yang memerlukan pengawasan ketat (8\%). Apabila telusur tersebut dibedakan antara ruangan yang melaporkan tepat waktu (17 ruangan), faktor terbesar adalah poin pelaporan form terlalu banyak $(29,41 \%)$, dan ruangan yang tidak mengumpulkan tepat waktu (8 ruangan), faktor terbesar juga poin pelaporan yang terlalu banyak $(37,5 \%)$.

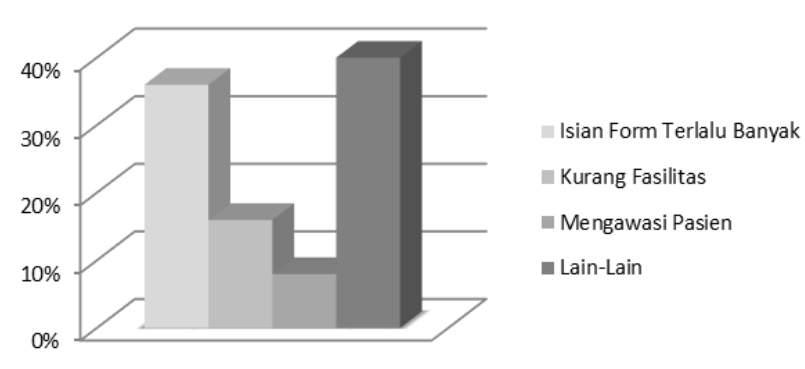

Grafik 2. Penyebab keidaktepatan waktu pengembalian form

\section{DISKUSI}

Hasil menunjukkan peningkatan ketepatan waktu pengembalian form pelaporan PPI sesudah sosialisasi kurang bermakna dengan peningkatan sebesar 3,57\%. Hal ini sesuai dengan suatu studi yang mengidentifikasi faktorfaktor yang mempengaruhi kurangnya kinerja surveilans di sebuah rumah sakit disamping kurangnya sosialisasi program kerja adalah belum ada dukungan manajemen rumah sakit, dan kurangnya pengawasan pimpinan (10). Kurang bermaknanya peningkatan pengembalian laporan PPI tersebut juga dimungkinkan karena sosialisasi belum dilakukan secara rutin dan belum dinilai secara terus menerus.

Beberapa faktor yang mempengaruhi keterlambatan pengembalian form adalah karena isian form terlalu banyak, kurangnya ketersediaan fasilitas, dan alasan pasien yang membutuhkan perhatian khusus. Faktor terbesar di sini adalah karena isian form terlalu banyak (36\%). Infection Prevention and Control Link Nurse (IPCLN) tidak dapat menyelesaikan seluruh isian dalam satu hari, sehingga kenyataan yang terjadi adalah pada saat akhir bulan masih banyak isian yang kosong, dan IPCLN baru mengisi dan melengkapi form tersebut pada akhir bulan. Form yang diisi pada akhir bulan berarti tidak berdasarkan hasil observasi, dan kemungkinan pengumpulan form menjadi melebihi batas waktu pengembalian. Batas waktu pengembalian ini penting karena IPCN lah yang menganalisis hasil capaian dari tiap-tiap laporan dari ruangan instalasi rawat inap, dan setiap tanggal 10 dilaporkan kepada komite penjamin mutu rumah sakit dan direksi. Hal ini mempengaruhi capaian indikator mutu rumah sakit yang menargetkan agar pelaporan tersebut $\geq 75 \%$ supaya menghasilkan data yang valid dan reliabel, sejalan dengan misi RSJ Dr. Radjiman Wediodiningrat ke-3 yaitu mengembangkan pendidikan, pelatihan dan penelitian yang terintegrasi untuk meningkatkan kualitas pelayanan.

Kurang sederhananya form dapat disebabkan perbedaan 
karakteristik pelayanan antar ruang sehingga membutuhkan form yang sesuai. Ruangan instalasi rawat inap di RSJ Dr. Radjiman Wediodiningrat yang menggunakan tindakan invasif hanya terdapat pada dua ruangan yaitu ruangan perawatan pasien umum, dan ruang perawatan pasien jiwa yang dalam keadaan sakit. Surveilans infeksi nosokomial umum hanya terbatas pada kedua ruangan tersebut. Pada 26 ruangan instalasi rawat inap lainnya tetap dapat terjadi infeksi nosokomial spesifik lainnya seperti scabies, diare, dan infeksi saluran nafas. $\mathrm{Hal}$ ini sebenarnya dapat ditindaklanjuti dengan cara memberikan form isian sesuai dengan kapasitas dan tindakan di ruangan tersebut agar tidak terkesan terlalu banyak pelaporan. Haustein menyebutkan beberapa faktor yang menunjang pelaporan yang baik antara lain adalah kemudahan pengumpulan data dan kejelasan batasan data (12), dengan demikian akan meningkatkan kinerja pencatatan dan pelaporan.

Form lain yang perlu disederhakan adalah form surveilans HAl's di setiap ruangan, karena form tersebut meliputi keseluruhan pencatatan infeksi nosokomial walaupun tidak dilakukan tindakan pemasangan infus atau kateter di ruangan rawat inap. Beberapa poin ditemukan tumpang tindih terhadap laporan dari unit kerja lain (komite mutu RS) seperti kepatuhan hand hygine.

Kurangnya fasilitas PPI juga menjadi faktor kendala

\section{DAFTAR PUSTAKA}

1. World Health Organization. Prevention of HospitalAcuired Infections. 2 edition. Malta: World Health Organization; 2002.

2. Graves N. Economics and Preventing HospitalAcquired Infection. Emerging Infectious Disease. 2004; 10(4): 561-566.

3. Weiss AJ and Elixhauser A. Overview of Hospital Stays in the United States. Agency for Healthcare Research and Quality. 2014; 425(1): 1-14.

4. Williams SC, Schmaltz SP, Morton DJ, Koss RG, and Loeb JM. Quality of Care in U.S. Hospitals as Reflected by Standardized Measures, 2002-2004. The New England Journal of Medicine. 2005; 353(3): 255-264.

5. Chung W, Oh SM, Suh T, Lee YM, Oh BH, and Yoon CW. Determinants of Length of Stay for Psychiatric Inpatients: Analysis of a National Database Covering the Entire Korean Elderly Population. Health Policy. 2009; 94(2): 120-128.

6. Tim Penulis Pendidikanku. Pengertian Sosialisasi Menurut Para Ahli. (Online) http://www. pendidikanku.net/2015/07/pengertiansosialisasi.html.

7. Dworkin NR, Drozdenko RG, and Goldstein J. pelaporan. Yang dimaksud dalam hal ini menurut hasil wawancara adalah salah satu isian form yang menjabarkan tentang fasilitas PPI di ruangan. Menurut IPCLN dan kepala ruangan, fasilitas pendukung PPI di ruangan masih sulit didapatkan, sehingga form fasilitas terkadang kosong. Kendala lainnya yaitu perawat dan IPCLN di ruangan yang terdapat banyak pasien dirawat, memprioritaskan untuk mengawasi pasien terutama yang dalam masa akut, karena pasien lebih membutuhkan pengawasan dan perawatan sehingga terkadang lupa atau menunda pengisian laporan.

Kegiatan pencatatan dan pelaporan form PPI di RSJ Dr. Radjiman Wediodiningrat masih terdapat kendala, yaitu rendahnya angka pengembalian form dari ruangan instalasi rawat inap ke IPCN. Faktor terbesar yang mempengaruhi ketidaktepatan waktu pengembalian form PPI dari instalasi rawat inap ke IPCN adalah karena poin isian form terlalu banyak, dan poin isian tersebut tidak seluruhnya sesuai dengan yang dilaksanakan di ruangan, sehingga memerlukan penyederhanaan form atau pendistribusian form yang lebih efektif di setiap ruangan karena perbedaan gambaran kegiatan di masing-masing ruangan. Disamping penyederhanaan dan penyesuaian form upaya sosialisasi perlu dilakukan secara berkelanjutan ditunjang dengan monitoring dan evaluasi untuk menunjang kinerja PPI.

Managerial Socialization in Short Term Hospital: $A$ Descriptive Analysis. Problems and Perspectives in Management. 2010; 8(2): 94-100.

8. King RC, Xia W, Quick JC, and Sethi V. Socialization and Organizational Outcomes of Information Technology Professionals. Career Development International. 2005;10(1):26-51.

9. Saeed T, Mansor NNA, Siddique S, Sameera S, Haq MA, and Ishaq HM. Organizational Socialization: Individual and Organizational Consequences. International Journal of Academic Research. 2012; 4(3): 96-101.

10. Mustariningrum DLT, Koeswo M, dan Ahsan. Kinerja IPCLN dalam Pencegahan dan Pengendalian Infeksi Rumah Sakit: Peran Pelatihan, Motivasi Kerja, dan Supervisi. Jurnal Aplikasi Manajemen. 2014; 13(4): 643-652.

11. Mishra S. Laswell's Communication Model. (Online). https://www.businesstopia.net/communication/lass well-communication-model. [diakses tanggal 14 Maret 2016].

12. Haustein $\mathrm{T}$, Gastmeier $\mathrm{P}$, Holmes $\mathrm{A}$, et al. Use of Benchmarking and Public Reporting for Infection Control in Four High-Income Countries. The Lancet Infectious Disease. 2011; 11(6): 471-481. 